\title{
BMJ Open Associations of workplace violence and psychological capital with depressive symptoms and burn-out among doctors in Liaoning, China: a cross- sectional study
}

\author{
Guoyuan Sui, ${ }^{1,2}$ Guangcong Liu, ${ }^{3}$ Lianqun Jia, ${ }^{1}$ Lie Wang, ${ }^{2}$ Guanlin Yang ${ }^{1}$
}

To cite: Sui G, Liu G, Jia L, et al. Associations of workplace violence and psychological capital with depressive symptoms and burn-out among doctors in Liaoning, China: a cross-sectional study. BMJ Open 2019;9:e024186. doi:10.1136/ bmjopen-2018-024186

- Prepublication history for this paper is available online. To view these files, please visit the journal online (http://dx.doi org/10.1136/bmjopen-2018024186).

Received 10 June 2018 Revised 24 February 2019 Accepted 27 February 2019
Check for updates

(C) Author(s) (or their employer(s)) 2019. Re-use permitted under CC BY-NC. No commercial re-use. See rights and permissions. Published by BMJ.

For numbered affiliations see end of article.

Correspondence to Professor Guanlin Yang; yang_guanlin@163.com and Lie Wang;

wangliew108@163.com

\section{ABSTRACT}

Objectives The purpose of this study was to (1) Identify the prevalence of workplace violence among doctors in Liaoning, China. (2) Examine the relationships between workplace violence and psychological capital with depressive symptoms and burn-out in Chinese doctors. Design A quantitative, cross-sectional study. Setting Eight hospitals in Liaoning Province were surveyed using a self-reported questionnaire. Participants The study population comprised 1800 doctors. Ultimately 1392 doctors completed valid questionnaires with a response rate of $77.3 \%$. Results The prevalence of workplace violence was $77.5 \%$. Compared with other types of workplace violence, the prevalence of psychological aggression was the highest $(72.7 \%)$. Workplace violence (depressive symptoms: $\beta[95 \% \mathrm{Cl}]=0.11[0.06,0.16]$; emotional exhaustion: $\beta[95 \% \mathrm{Cl}]=0.18[0.13,0.23]$; depersonalisation: $\beta[95 \% \mathrm{Cl}]=0.17[0.12,0.22])$ and psychological capital (depressive symptoms: $\beta[95 \% \mathrm{Cl}]=-0.32[-0.37,-0.27]$; emotional exhaustion: $\beta[95 \% \mathrm{Cl}]=-0.23[-0.28,-0.18]$; depersonalisation: $\beta[95 \% \mathrm{Cl}]=-0.23[-0.28,-0.18])$ were associated with depressive symptoms and burn-out. Workplace violence increased the level of depressive symptoms and burn-out by damaging psychological capital (depressive symptoms: $\mathrm{a}^{*} \mathrm{~b}=1.61$, bias-corrected and accelerated [BCa] $95 \% \mathrm{Cl}$ 1.08 to 2.25; emotional exhaustion: $a^{\star} b=1.29, \mathrm{BCa} 95 \% \mathrm{Cl}$ 0.86 to 1.83 ; depersonalisation: $\mathrm{a}^{*} \mathrm{~b}=0.70, \mathrm{BCa} 95 \% \mathrm{Cl}$ 0.45 to 1.00 ).

Conclusions In China, most doctors will be exposed to workplace violence, especially psychological aggression. A safer work environment and psychological capital development may be considered in prevention and treatment strategies for improving mental health.

\section{BACKGROUND}

Workplace violence was defined as 'incidents where staff were abused, threatened or assaulted in circumstances related to their work, including commuting to and from work, involving an explicit or implicit threat to their safety, well-being or health'. International
Strengths and limitations of this study

- This study had a large sample size and high response rates.

- The sample was representative and was distributed in five regions of Liaoning Province.

- We used the asymptotic and resampling strategies developed by Preacher and Hayes to examine the mediating role of psychological capital in the relationships between workplace violence and depressive symptoms and burn-out.

- Due to the cross-sectional design, this survey was not able to determine causality among variables.

- Because workplace violence, psychological capital, depressive symptoms and burn-out measured were by a self-reported questionnaire, common reporting variance may affect the reported effects of workplace violence and psychological capital on depressive symptoms and burn-out.

Labour Office, International Council of Nurses, WHO and Public Services International have reported that approximately a quarter of the total number of violent incidents in all workplaces occurs in a hospital. ${ }^{2}$ The Occupational Safety and Health Administration reported that from 2011 to 2013, the number of workplace violence incidents averaged nearly 24000 annually, with approximately $75 \%$ occurring in the healthcare setting. ${ }^{3}$ In Turkey, $78.1 \%$ of doctors suffered workplace violence. ${ }^{4}$ In Iran, almost $90 \%$ of residents experienced violence. ${ }^{5}$ Hospital violence has become an increasingly serious public health problem worldwide and is also common in China, which has attracted considerable attention.

According to the China Statistical Yearbook, the number of doctors is 2.31 per 1000 persons. ${ }^{6}$ A study reported that human resources in Chinese hospitals were insufficient, which may cause strain on doctors. ${ }^{7}$ 
With the development of medicine, most doctors are busy with technical challenges and thus ignore patients' inner feelings in clinical settings. ${ }^{8}$ In addition, in China patients often complain about extensive medical costs. ${ }^{9}$ Because the price of medical services is under governmental control, Chinese doctors receive low benefits from medical services. ${ }^{10}$ As a result, to make more profits, some doctors may provide unnecessary treatment to patients. ${ }^{10}$ Although the government has taken some measures to address this issue, it still causes adverse effects. ${ }^{9}$ All of the above factors may lead to an unharmonious doctor-patient relationship, which may put Chinese doctors at high risk of workplace violence. ${ }^{11}$ Sun et al found that $83.4 \%$ of doctors experienced workplace violence from 30 provinces of China. ${ }^{9}$ Yao et al reported that $63.2 \%$ of doctors suffered workplace violence in Henan Province, China. ${ }^{12}$ The results of previous studies varied considerably. ${ }^{13}$ Inconsistency in the existing data may make interpretation of the results quite difficult. ${ }^{14}$ A meta-analysis showed that the prevalence of workplace violence targeting doctors was $61.1 \%$ (95\% CI $56.1 \%$ to $66.1 \%) .{ }^{13}$ This study further estimated the prevalence of workplace violence among doctors in China.

Workplace violence was found to be a risk factor for depressive symptoms and burn-out. ${ }^{15} 16$ Depressive symptoms and burn-out affected doctors' quality of life, and threatened patients' safety and healthcare quality. ${ }^{17-19}$ Thus, improving the mental health of doctors is important for both the doctors themselves and their patients. Although the impacts of hospital violence on depressive symptoms and burn-out have been explored, most studies involved medical staff or nurses. ${ }^{20-22}$ More studies targeting doctors may be needed. In addition, the fear of violence was reported to mediate the effects of workplace violence on mental health and emotional wellbeing. ${ }^{23}{ }^{24}$ Workplace violence had both direct and indirect effects on mental health. In-depth research on both the direct and indirect effects of workplace violence on depressive symptoms and burn-out should be conducted to establish more effective measures for improving mental health. ${ }^{15} 162324$

Psychological capital refers to an individual's positive psychological state of development. ${ }^{25}$ It consists of self-efficacy, hope, optimism and resilience. ${ }^{25}$ Based on Bandura's Social Cognitive Theory, self-efficacy means confidence and the ability to finish challenging tasks; hope involves willpower to achieve a goal and the capacity for tackling challenges; according to Seligman, optimism is the way in which an individual understands past experiences; resilience reflects adaptability to positive or negative environment. ${ }^{26}$ Based on the above theory, individuals with high levels of psychological capital are adaptable to changing demands and demonstrate emotional stability when faced with adversity. ${ }^{25}{ }^{26}$ Most studies have found that psychological capital may help individuals cope with depressive symptoms and burn-out. ${ }^{27}{ }^{28}$ Psychological capital is state-like and can be changed. ${ }^{25}$ Liu et al found that psychological capital mediated the relationship between effort-reward imbalance and depressive symptoms. ${ }^{27}$ Wang et al reported that work-family conflict increased the level of burn-out by damaging psychological capital. ${ }^{28}$ Thus psychological capital may mediate the relationships of workplace violence with depressive symptoms and burn-out in doctors.

The aim of the present study was to (1) Identify the prevalence of workplace violence among doctors in Liaoning, China. (2) Examine the relationships between workplace violence, psychological capital and depressive symptoms, and burn-out in Chinese doctors.

\section{METHOD \\ Study population}

Based on previous studies, the prevalence of depressive symptoms was 30\%-60\%; for burn-out, the SDs of emotional exhaustion, depersonalisation and personal accomplishment were 11.76, 4.76 and 10.96, respectively. ${ }^{29-31}$ Tolerance errors of emotional exhaustion and personal accomplishment were set to 1 ; the tolerance error of personal accomplishment was set to 0.50 , and the tolerance error of depressive symptoms was set to $0.03 .^{32} 33$ Finally according to the prevalence and tolerance error of depressive symptoms $(\mathrm{P}=30 \%, d=0.03, \mathrm{Za}=1.96)$, the sample size was 897 . If the design effect was set to 1.50 and the effective response rate was set to $75 \%,{ }^{34} 1793$ individuals needed to be included. Therefore, 1800 doctors were surveyed.

During June-July 2015, a cross-sectional survey was conducted in Liaoning Province. According to the geographical division of Liaoning Province, the entire province was divided into five regions. One city in each region was randomly selected (Dandong, Fuxin, Anshan, Fushun and Shenyang). Based on the number of 'grade two and above' general hospitals ( $>100$ beds) and population size, one 'grade two and above' general hospital was randomly selected in Dandong, Fuxin, Anshan and Fushun, respectively, and four 'grade two and above' general hospitals were randomly selected in Shenyang (a total of eight hospitals). Based on the estimated sample size, $225(1800 / 8)$ individuals who worked for 12 months or longer were selected in every hospital. Self-administered questionnaires were directly distributed to 1800 doctors after obtaining written informed consent. The questionnaire in which missing values exceeded $20 \%$ was regarded as invalid. We received an effective response from 1392 doctors with an effective response rate of $77.3 \%$.

\section{Questionnaires}

Depressive symptoms (outcome variable)

The Center for Epidemiology Studies Depression Scale (CES-D, 20 items) is used for epidemiological research and can be responded to on a 4-point Likert Scale, with response categories ranging from 'rarely or none of the time' ( 0 points) to 'most or all of the times' ( 3 points). ${ }^{35}$ It is a self-report questionnaire that is used to measure 
current depressive symptoms in the general population. The CES-D is an international common scale and has been translated, back translated and revised to make its items culturally and linguistically applicable in China. The Chinese version of the CES-D has shown good reliability, and validity and has been widely used in Chinese populations. ${ }^{30}$ Higher scores indicate higher levels of depressive symptoms. In this study, Cronbach's $\alpha$ for CES-D was 0.92 .

\section{Burn-out (outcome variable)}

The Maslach Burnout Inventory Human Services Survey (MBI-HSS) is a 22-item scale. Responses are recorded on a 7-point scale, with response categories ranging from 'never' (0 point) to 'every day' (6 points). ${ }^{36}$ MBI-HSS includes three dimensions: emotional exhaustion (nine items), depersonalisation (five items) and personal accomplishment (eight items). Higher scores for emotional exhaustion and depersonalisation and lower scores for the personal accomplishment indicate higher levels of burn-out. The MBI-HSS is an international common scale, and the Chinese version of the MBI-HSS has good reliability and validity, and has been widely used in Chinese populations. ${ }^{37}$ In this study, Cronbach's $\alpha$ for emotional exhaustion, depersonalisation and personal accomplishment were $0.89,0.80$ and 0.88 , respectively.

\section{Workplace violence (predictor variable)}

Two dimensions of the workplace violence scale (verbal sexual harassment and sexual assault) adapted by Peixi Wang and the workplace violence scale designed by Schat et al were adopted. ${ }^{1538}$ For the workplace violence scale adapted by Peixi Wang, verbal sexual harassment and sexual assault each contain one item, respectively. The workplace violence scale designed by Schat $e t$ al includes three dimensions: physical violence at work (eight items), psychological aggression at work (three items) and vicarious violence at work (five items). Each item can be responded to on a 4-point scale from 0 for no experience, one for experiencing once, 2 for two to three experiences, and 3 for four or more experiences. Based on the definition of workplace violence in our study (incidents where staff are abused, threatened or assaulted in circumstances related to their work, including commuting to and from work, involving an explicit or implicit threat to their safety, well-being or health), ${ }^{1}$ we deleted two items from 'physical violence at work' and all items from 'vicarious violence at work'. Finally the workplace violence scale in our study included 11 items. The original scale included four dimensions: physical violence at work, psychological aggression, verbal sexual harassment and sexual assault. Some scholars divided 'physical violence at work' into 'physical assault' and 'threat', and thus, the workplace violence scale included five factors. ${ }^{38}$ Based on the four-factor and the five-factor models, we performed confirmatory factor analysis. We found that goodness-of-fit indexes of the uncorrected five-factor structure were better than those of the uncorrected four-factor structure (uncorrected four-factor structure:
Goodness of Fit Index (GFI) $=0.88$, Compare Fix Index $(\mathrm{CFI})=0.93$, Incremental Fit Index $\quad(\mathrm{IFI})=0.93$, Root Mean Square Error of Approximation (RMSEA) $=0.13$, Tucker-Lewis Index (TLI) $=0.91$, Standard Root Mean Square Residual $(\mathrm{SRMR})=0.05$; uncorrected five-factor structure: GFI $=0.91, \mathrm{CFI}=0.95$, IFI $=0.95$, RMSEA $=0.12$, TLI $=0.92$, SRMR $=0.05$ ). Finally, goodness-of-fit indexes of the corrected five-factor structure were relatively good (GFI=0.94, CFI=0.97, IFI=0.97, RMSEA $=0.09$ TLI=0.95, SRMR=0.04). Cronbach's $\alpha$ was 0.90 .

\section{Psychological capital (mediating variable)}

Psychological capital was measured with a 24-item Psychological Capital Questionnaire (PCQ-24), which was developed by Luthans et al. ${ }^{26}$ PCQ-24 includes four dimensions: self-efficacy (six items), hope (six items), resilience (six items) and optimism (six items). Each of the items can be responded to on a 6-point Likert scale, with response categories ranging from 'strongly disagree' (1 point) to 'strongly agree' (6 points). Higher scores indicate higher levels of psychological capital. PCQ-24 is an international common scale, and the Chinese version of PCQ-24 has good reliability and validity and has been widely used in Chinese populations. ${ }^{39}$ In this study, Cronbach's $\alpha$ was 0.88 .

\section{Demographic characteristics (control variables)}

Demographic factors included the following: age, gender (male, female), marriage (single, married/cohabitation, widow/divorced/separated), education (junior college or lower, college, graduate or higher), only child (yes, no), smoking (no, ever, yes), drinking (yes, no), rank (resident, attending doctor, associate chief doctor, chief doctor), division (internal medicine, surgical department, department of obstetrics and gynaecology, ancillary department, other department), weekly work time ( $\leq 40$ hours/week, $>40$ hours/week), income $(\leq ¥ 3000$, $¥ 3001-4000$, ¥4001-5000, >¥5000), shift work (yes, no) and night shift (yes, no).

\section{Statistical analyses}

For the categorical variables, groups for which the response rate was $<5 \%$ were merged. In our study, only 37 (2.7\%) participants belonged to the 'widow/divorced/ separated' group, and thus this group was combined with the 'single' group. Univariate analysis of depressive symptoms and burn-out in relation to categorical variables was examined by t-tests and one-way analyses of variance (ANOVAs). Univariate analysis of depressive symptoms and burn-out in relation to continuous variables was tested by Pearson's correlation analysis.

We performed hierarchical linear regression analyses to examine the effects of workplace violence and psychological capital on depressive symptoms and burn-out. Except for gender and age, variables related to depressive symptoms and burn-out $(\mathrm{p}<0.05)$ in t-tests or one-way ANOVAs were entered in the model. 


\begin{tabular}{|c|c|}
\hline Variables & $\mathbf{N}(\%)$ \\
\hline \multicolumn{2}{|l|}{ Violence styles } \\
\hline Physical violence & $469(33.7)$ \\
\hline Psychological aggression & 1012 (72.7) \\
\hline Threat & $433(31.1)$ \\
\hline Verbal sexual harassment & $272(19.5)$ \\
\hline Sexual assault & $175(12.6)$ \\
\hline \multicolumn{2}{|l|}{ Accumulated violence } \\
\hline Zero type & $315(22.6)$ \\
\hline One type & $483(34.7)$ \\
\hline Two types & $202(14.5)$ \\
\hline Three types & $202(14.5)$ \\
\hline Four types & $82(5.9)$ \\
\hline Five types & $108(7.8)$ \\
\hline Division & $\begin{array}{l}\text { Workplace violence } \\
\text { (N [\%]) }\end{array}$ \\
\hline Internal medicine & $378(80.8)$ \\
\hline Surgical department & $245(83.3)$ \\
\hline $\begin{array}{l}\text { Department of obstetrics and } \\
\text { gynaecology }\end{array}$ & $66(76.7)$ \\
\hline Ancillary department & 139 (69.5) \\
\hline Other department & $251(73.0)$ \\
\hline
\end{tabular}

Based on the results of the hierarchical linear regression analyses, we further used the asymptotic and resampling strategies developed by Preacher and Hayes to examine the mediating role of psychological capital in the relationships between workplace violence and depressive symptoms and burn-out. All of the above analyses were conducted using SPSS V.13.0. A two-tailed probability value of $<0.05$ was considered statistically significant. Missing values were addressed with mean substitution. ${ }^{40}$

\section{Patient and public involvement}

Patients or public were not involved in this study.

\section{RESULTS}

\section{Characteristics of workplace violence among doctors}

The characteristics of workplace violence among doctors are shown in table 1 . The prevalence of workplace violence was $77.5 \%$. Approximately $72.7 \%$ of participants encountered psychological aggression. The prevalence of workplace violence from highest to lowest was physical violence $(33.7 \%)$, threat $(31.1 \%)$, verbal sexual harassment $(19.5 \%)$ and sexual assault (12.6\%). Additionally, $34.7 \%$ of participants experienced one type of violence, $14.5 \%$ of participants encountered two types of violence and $14.5 \%$ of participants suffered three types of violence. The prevalence of workplace violence was highest $(83.3 \%)$ in the surgical department and lowest $(69.5 \%)$ in the ancillary department.

\section{T-tests or one-way ANOVAs of depressive symptoms and burn-out in relation to categorical variables}

The average age was $(38.90 \pm 8.81)$ years. Educational level, weekly work time, shift work, night shift, division, income and workplace violence were significantly associated with depressive symptoms $(\mathrm{p}<0.05)$. Marriage, educational level, weekly work time, shift work, night shift, division and workplace violence were significantly associated with emotional exhaustion $(\mathrm{p}<0.05)$. Educational level, weekly work time, shift work, night shift, division and workplace violence were significantly associated with depersonalisation $(\mathrm{p}<0.05)$. Gender, marriage, educational level, weekly work time, rank, division, income and workplace violence were significantly associated with personal accomplishment $(\mathrm{p}<0.05)$. The above results are shown in table 2 .

\section{Pearson's correlation analysis of depressive symptoms and burn-out in relation to continuous variables}

The correlation analysis showed that age was significantly correlated with personal accomplishment $(r=0.07$, $\mathrm{p}<0.05)$. Psychological capital was significantly associated with depressive symptoms $(\mathrm{r}=-0.35, \mathrm{p}<0.05)$ and burn-out (emotional exhaustion: $\mathrm{r}=-0.28, \mathrm{p}<0.05$; depersonalisation: $\mathrm{r}=-0.27, \mathrm{p}<0.05$; personal accomplishment: $\mathrm{r}=0.26, \mathrm{p}<0.05)$.

\section{Hierarchical linear regression analysis results, with} depressive symptoms and job burn-out as the criterion variables

In step 1 of the hierarchical linear regression analysis, demographic characteristics were used as predictors. In step 2, workplace violence was added and in step 3, psychological capital was added. Workplace violence was positively associated with depressive symptoms $(\beta[95 \% \mathrm{CI}]=0.11 \quad[0.06,0.16], \mathrm{p}<0.05)$ and two dimensions of burn-out (emotional exhaustion: $\beta[95 \% \mathrm{CI}]=0.18[0.13,0.23], \mathrm{p}<0.05$; depersonalisation: $\beta[95 \% \mathrm{CI}]=0.17 \quad[0.12,0.22], \quad \mathrm{p}<0.05) . \quad$ Psychological capital was negatively associated with depressive symptoms $(\beta[95 \% \mathrm{CI}]=-0.32 \quad[-0.37,-0.27], \quad \mathrm{p}<0.05)$ and two dimensions of burn-out (emotional exhaustion: $\beta[95 \% \mathrm{CI}]=-0.23 \quad[-0.28,-0.18], \mathrm{p}<0.05$; depersonalisation: $\beta[95 \% \mathrm{CI}]=-0.23[-0.28,-0.18], \mathrm{p}<0.05)$. The above results showed that workplace violence and psychological capital were associated with depressive symptoms and two dimensions of burn-out (emotional exhaustion and depersonalisation) (table 3 ).

Regression analysis results, with depressive symptoms and two dimensions of burn-out (emotional exhaustion and depersonalisation) as outcomes and psychological capital as a mediator

In the regression equation, workplace violence was used as a predictor, and depressive symptoms and burn-out were used as outcomes (figure 1). The first step in the analysis was to explore the associations of workplace 
Table 2 Univariate analysis of depressive symptoms and burn-out in relation to categorical variables

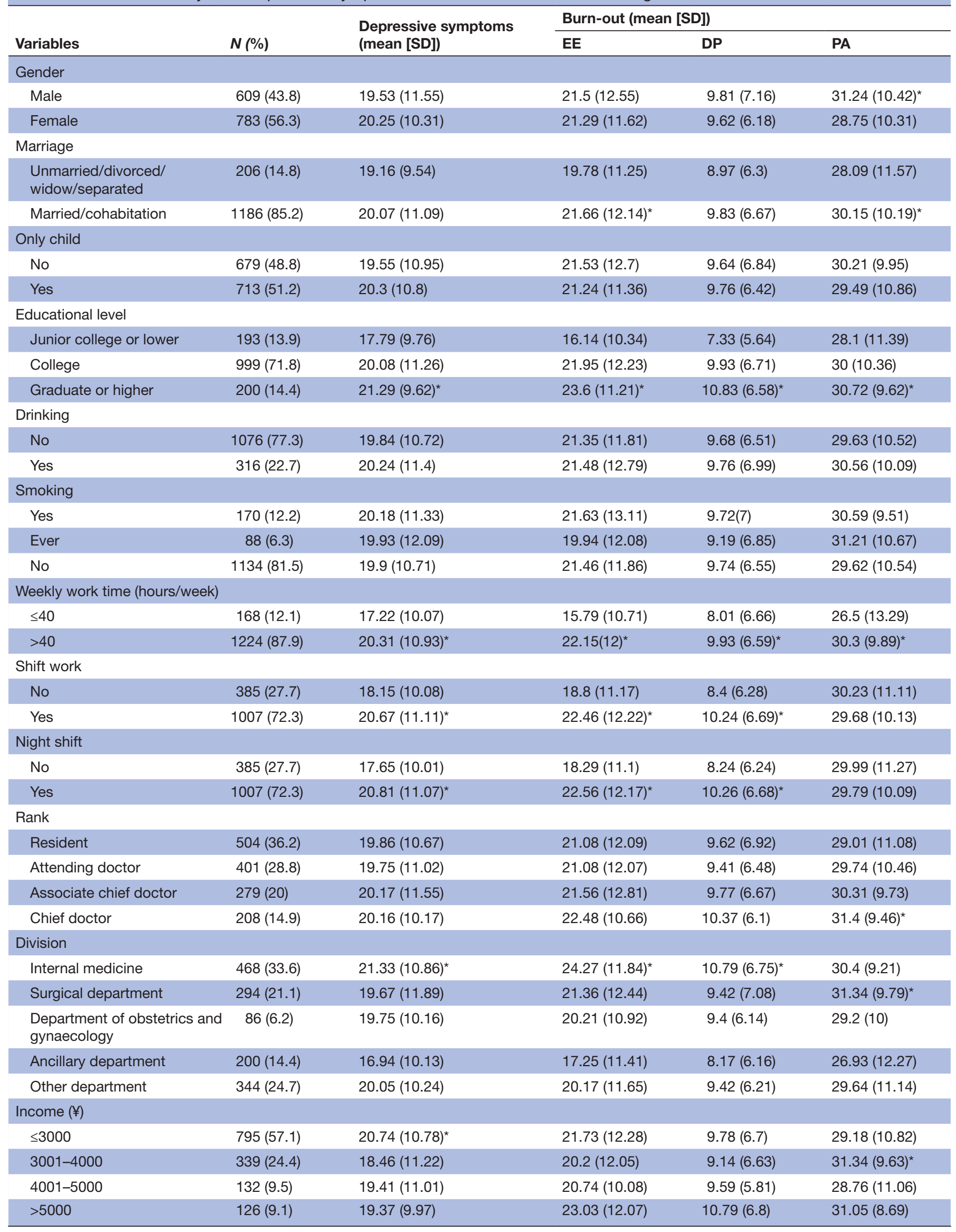


Table 2 Continued

\begin{tabular}{|c|c|c|c|c|c|}
\hline \multirow[b]{2}{*}{ Variables } & \multirow[b]{2}{*}{$N(\%)$} & \multirow{2}{*}{$\begin{array}{l}\text { Depressive symptoms } \\
\text { (mean [SD]) }\end{array}$} & \multicolumn{3}{|c|}{ Burn-out (mean [SD]) } \\
\hline & & & EE & DP & PA \\
\hline \multicolumn{6}{|c|}{ Workplace violence } \\
\hline Yes & $1079(77.5)$ & $20.72(10.72)^{\star}$ & $22.79(11.67)^{\star}$ & $10.38(6.32)^{\star}$ & $29.79(9.16)$ \\
\hline
\end{tabular}

${ }^{*} \mathrm{P}<0.05$.

DP, depersonalisation; EE, emotional exhaustion; PA, personal accomplishment.

violence with depressive symptoms and burn-out (the c path). The second step was to explore the mediating role of psychological capital (the a*b products), and c' path coefficient represented the effects of workplace violence on depressive symptoms and burn-out after psychological capital was added in the second step. When the c' path coefficient was smaller than the c path coefficient or became statistically insignificant, a mediating effect may have existed. Based on 5000 bootstrap samples, a bias-corrected and accelerated $95 \%$ CI (BCa 95\% CI) of each a*b product was explored, and a BCa $95 \%$ CI without 0 meant a significant mediating effect.

Workplace violence was significantly associated with psychological capital (the a path, $\mathrm{p}<0.05$ ). Psychological capital was significantly negatively associated with depressive symptoms and two dimensions of burn-out after controlling for workplace violence (the b path, $p<0.05)$. The c' path coefficient was still significant in burn-out $(p<0.05)$, but less than the c path coefficient. The c' path coefficient was not significant in depressive symptoms. Psychological capital mediated the relationships of workplace violence with depressive symptoms $\left(\mathrm{a}^{*} \mathrm{~b}=1.61\right.$, BCa 95\% CI 1.08 to 2.25; $\mathrm{p}<0.05)$ and two dimensions of burn-out (emotional exhaustion: $\mathrm{a} * \mathrm{~b}=1.29$, BCa $95 \%$ CI 0.86 to $1.83, \mathrm{p}<0.05$; depersonalisation: $\mathrm{a} * \mathrm{~b}=0.70$, BCa $95 \%$ CI 0.45 to $1.00, \mathrm{p}<0.05)$. The above results showed that workplace violence increased the level of depressive symptoms and burn-out by damaging psychological capital (table 4).

\section{DISCUSSION}

This study explored the prevalence of workplace violence among doctors in China, the associations of workplace violence and psychological capital with depressive symptoms and burn-out, and the mediating roles of psychological capital. The sample size (1392 doctors) was large and the effective responsive rate in this study was $77.3 \%$, which was greater than $70 \%$, which was considered acceptable for the questionnaire survey. ${ }^{41}$ The workplace violence scale in this study had good reliability and validity. These findings may increase the generalisation of our study conclusion across the entire Liaoning Province. In this study, the most important discovery was the discovery that workplace violence increased the level of depressive symptoms and burn-out by damaging psychological capital.
The prevalence of workplace violence among doctors was $77.5 \%$. Of all participants, most suffered one type of violence. Compared with other types of workplace violence, doctors were more prone to psychological aggression, which was similar to the findings of a previous study. ${ }^{10}$ The prevalence of workplace violence in the surgical department was highest. Based on above statements, most doctors will be exposed to workplace violence, especially psychological aggression in Liaoning, China.

The results demonstrated that workplace violence was positively associated with depressive symptoms and two dimensions of burn-out (emotional exhaustion and depersonalisation). Doctors who suffered workplace violence were more likely to experience higher levels of depressive symptoms and burn-out. These results were consistent with the findings of previous studies. ${ }^{162242}$ For example, Gong et al found that workplace violence was associated with depressive symptoms in nurses, ${ }^{16}$ and Chen $e t$ al indicated that workplace violence may increase the risk of burn-out in medical staff. ${ }^{22}$ Workplace violence as a stressor may pose a threat to the life, safety and esteem of doctors, which may cause emotional distress and thereby deteriorate mental health. These findings should urge hospital administrators to realise the risk of workplace violence. Efforts should be made to develop interventions for decreasing workplace violence in order to decrease depressive symptoms and burn-out in doctors. For example, hospital administrators could offer vocational trainings for doctors on improving technical skills and developing empathy. These may make doctors more adaptable to high tech environments, and contribute to establishing a good relationship between doctors and patients. Additionally, hospitals should take effective measures to ensure hospital environments are safe, such as installing alarm systems and hiring security.

In this study, we found that psychological capital had negative effects on depressive symptoms and two dimensions of burn-out (emotional exhaustion and depersonalisation), which were consistent with the results of previous studies. ${ }^{27}{ }^{28}$ In addition, previous studies showed that psychological capital mediated the relationships between work-family conflict and burn-out, effort-reward imbalance and depressive symptoms, and subject well-being and burn-out. ${ }^{27} 2843$ This is the first study to examine the mediating role of psychological capital 
Table 3 Hierarchical linear regression analysis results, with depressive symptoms and job burn-out as the criterion variable, respectively

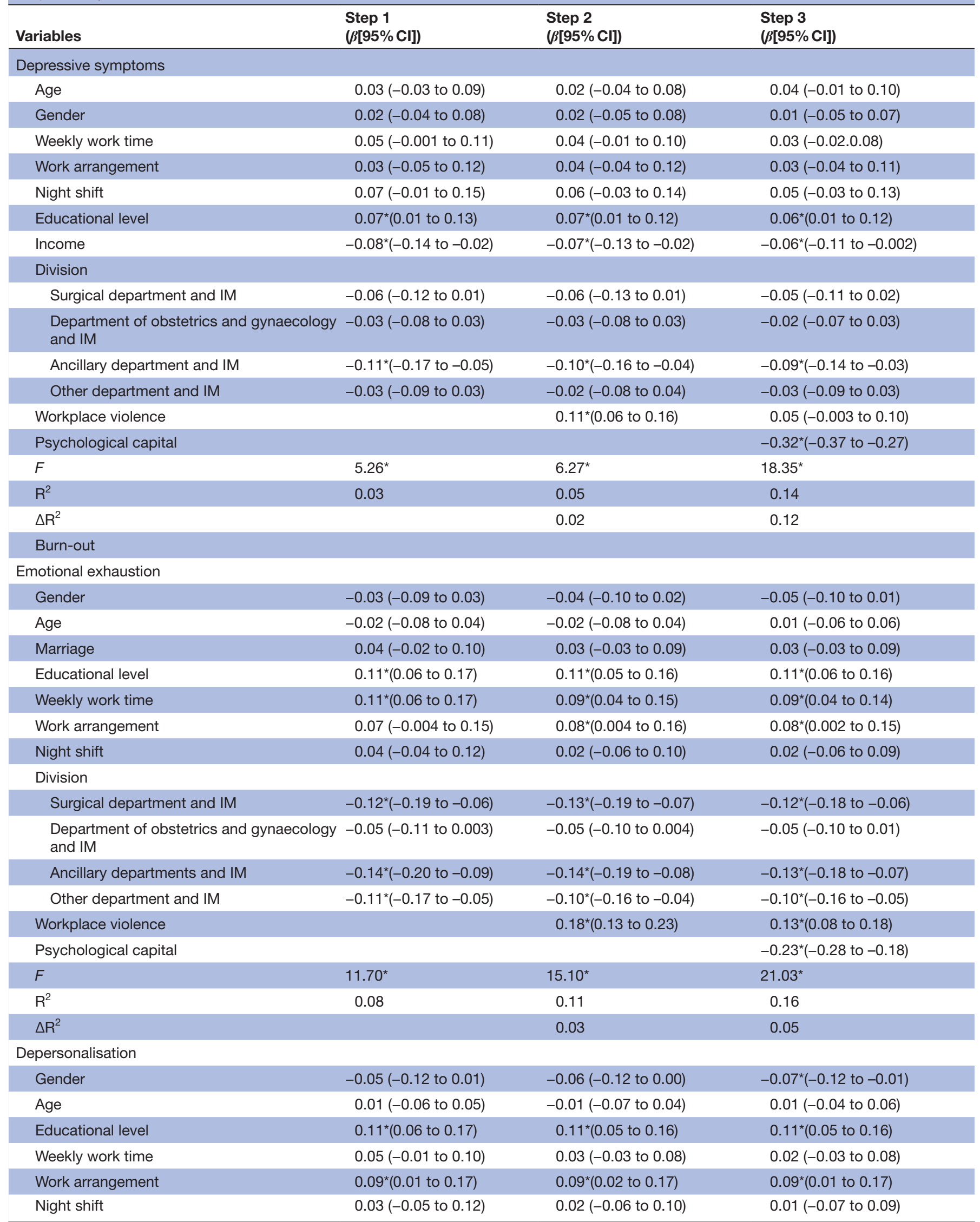




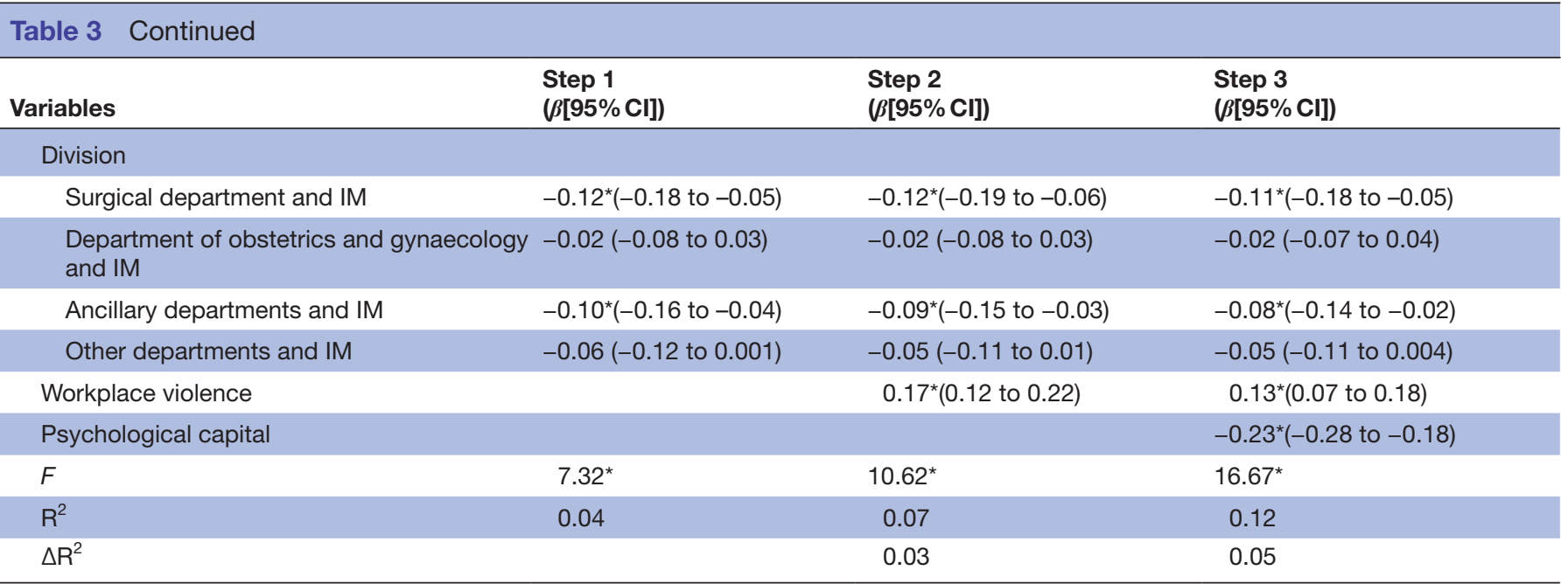

${ }^{*} \mathrm{P}<0.05$,

F, F test; IM, internal medicine; $R^{2}$, adjusted coefficient of determination; $\Delta R^{2}$, the amount of change in adjusted coefficient of determination.

in the relationships of workplace violence with depressive symptoms and burn-out. We found that psychological capital mediated the relationships of workplace violence with depressive symptoms and two dimensions of burn-out (emotional exhaustion and depersonalisation). Workplace violence can increase the level of depressive symptoms and burn-out of doctors by damaging their psychological capital. Therefore, efforts should be made to develop interventions to improve psychological capital
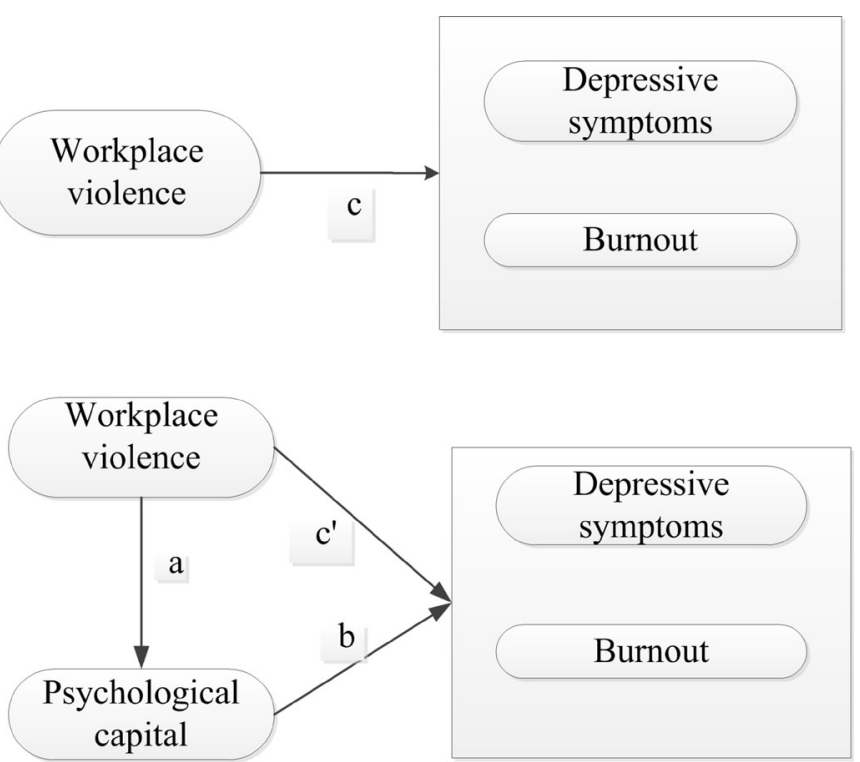

Figure 1 Theory model of the mediating role of psychological capital on the associations between workplace violence, depressive symptoms and burn-out. a: associations of workplace violence with psychological capital; b: associations of psychological capital with depressive symptoms and burn-out after controlling for workplace violence; c: associations of workplace violence with depressive symptoms and burn-out; $c^{\prime}$ : associations of workplace violence with depressive symptoms and burn-out after adding psychological capital as a mediator. to reduce depressive symptoms and burn-out in doctors. However, in China, advancing medical technology and financial capital have attracted increasing attention, and human resources have attracted little attention. Psychological capital as a positive resource is considered to be state-like and can be changed. ${ }^{25}$ In 2005 , Luthans et al proposed a psychological capital intervention model that improved the level of psychological capital in four aspects: self-efficacy, hope, resilience and optimism. Moreover, empirical studies conducted by Luthans et al showed that strategies can be adopted to improve the level of psychological capital, which, in turn, may improve job satisfaction and work performance. ${ }^{44}{ }^{45}$ However, to our knowledge, psychological capital training interventions aimed at improving mental health among Chinese doctors have not yet been conducted.

Several limitations must be mentioned. First, due to the cross-sectional design, this survey was not able to determine causality among variables. Therefore, all of these results need to be confirmed in longitudinal studies. Second, workplace violence, psychological capital, depressive symptoms and burn-out were measured by a self-reported questionnaire. Thus, common reporting variance may affect the results of effects of workplace violence and psychological capital on depressive symptoms and burn-out. Third, we only investigated doctors in Liaoning Province, so the results may not be fully representative of the entire situation in China. Future studies should conduct in-depth exploration in other provinces.

\section{CONCLUSIONS}

In China, most doctors would be exposed to workplace violence, especially psychological aggression. To our knowledge, this is the first study exploring the mediating role of psychological capital in the relationships of workplace violence with depressive symptoms and burn-out. Our findings demonstrated that workplace violence and 
Table 4 Regression analysis results, with depressive symptoms and two dimensions of burn-out (emotional exhaustion and depersonalisation) as outcomes and psychological capital as a mediator

\begin{tabular}{|c|c|c|c|c|c|}
\hline Variables & c & a & b & $c^{\prime}$ & $\begin{array}{l}\text { a*b } \\
\text { (BCa 95\% Cl) }\end{array}$ \\
\hline \multicolumn{6}{|l|}{ Model 1} \\
\hline Depressive symptoms & $2.85^{*}$ (1.48 to 4.21$)$ & $-0.36^{*}(-0.46$ to -0.27$)$ & $-4.42^{*}(-5.12$ to -3.72$)$ & $1.24(-0.08$ to 2.56$)$ & 1.61 (1.08 to 2.25$)$ \\
\hline \multicolumn{6}{|l|}{ Model 2} \\
\hline Emotional exhaustion & $5.15^{\star}$ (3.70 to 6.61$)$ & $-0.37^{\star}(-0.46$ to -0.27$)$ & $-3.51^{*}(-4.27$ to -2.75$)$ & $3.86^{\star}(2.42$ to 5.31$)$ & 1.29 (0.86 to 1.83$)$ \\
\hline \multicolumn{6}{|l|}{ Model 3} \\
\hline
\end{tabular}

Model 1: workplace violence as a predictor, psychological capital as a mediator, depressive symptoms as an outcome. Model 2: workplace violence as a predictor, psychological capital as a mediator, emotional exhaustion as an outcome. Model 3: workplace violence as a predictor, psychological capital as a mediator, depersonalisation as an outcome. ${ }^{*} \mathrm{P}<0.05$.

a, associations of workplace violence with psychological capital; $a^{\star} b$, the product of $a$ and $b$; $b$, associations of psychological capital with depressive symptoms and two dimensions of burn-out (emotional exhaustion and depersonalisation) after controlling for the predictor variables; $\mathrm{BCa} 95 \% \mathrm{Cl}$, bias-corrected and accelerated $95 \% \mathrm{Cl}$; c, associations of workplace violence with depressive symptoms and two dimensions of burn-out (emotional exhaustion and depersonalisation); c', associations of workplace violence with depressive symptoms and two dimensions of burn-out (emotional exhaustion and depersonalisation) after adding psychological capital as a mediator.

psychological capital were associated with depressive symptoms and burn-out. Psychological capital mediated the relationships of workplace violence with depressive symptoms and burn-out. A safer work environment and psychological capital development may be considered in prevention and treatment strategies for improving mental health.

\section{Author affiliations}

${ }^{1}$ Key Laboratory of Ministry of Education for Traditional Chinese Medicine VisceraState Theory and Applications, Liaoning University of Traditional Chinese Medicine, Shenyang, Liaoning, China

${ }^{2}$ School of Public Health, China Medical University, Shenyang, Liaoning, China ${ }^{3}$ Liaoning Key Laboratory of Urban Ecology, Shenyang Academy of Environmental Sciences, Shenyang, Liaoning, China

Acknowledgements The authors thank all the administrators in each selected hospital who helped us to get the written informed consent and to distribute the questionnaires.

Contributors GS took part in the conduct of the survey, performed all statistical analyses and the manuscript preparation. GL contributed to the conduct of the survey and the data analysis. LJ and LW contributed to data analysis and the interpretation of the data. GY and LW contributed to the conduct of the survey and the manuscript preparation. All authors have read and approved the final manuscript.

Funding The authors have not declared a specific grant for this research from any funding agency in the public, commercial or not-for-profit sectors.

Competing interests None declared.

Patient consent for publication Not required.

Ethics approval The procedures followed were approved by the ethical standards of the Committee on Human Experimentation of China Medical University.

Provenance and peer review Not commissioned; externally peer reviewed.

Data sharing statement No additional data are available.

Open access This is an open access article distributed in accordance with the Creative Commons Attribution Non Commercial (CC BY-NC 4.0) license, which permits others to distribute, remix, adapt, build upon this work non-commercially, and license their derivative works on different terms, provided the original work is properly cited, appropriate credit is given, any changes made indicated, and the use is non-commercial. See: http://creativecommons.org/licenses/by-nc/4.0/.

\section{REFERENCES}

1. Wynne R, Clarkin N, Cox T, et al. Guidance on the prevention of violence at work. Luxembourg: European Commission, DG-V, 1997.

2. International Labour Office/International Council of Nurses/World Health Organization/Public Services International. Framework guidelines for addressing workplace violence in the health sector. Geneva, Switzerland: International Labour Office, 2002.

3. Occupational Safety and Health Administration. Guidelines for preventing workplace violence for healthcare and social servic workers (OSHA,3148-04R. Washington, DC: OSHA, 2015.

4. Bayram B, Çetin M, Çolak Oray N, et al. Workplace violence against physicians in Turkey's emergency departments: a cross-sectional survey. BMJ Open 2017;7:e013568.

5. Hedayati Emam G, Alimohammadi H, Zolfaghari Sadrabad A, et al. Workplace violence against residents in Emergency Department and Reasons for not Reporting Them; a Cross Sectional Study. Emerg 2018;6:e7.

6. http://www.stats.gov.cn/tjsj/ndsj/2017/indexch.htm (Accessed 13 Oct 2018)

7. Anand S, Fan VY, Zhang J, et al. China's human resources for health: quantity, quality, and distribution. Lancet 2008;372:1774-81.

8. Liu GZ, Zhang ZJ, Ch M, et al. Investigation and analysis of clinical doctors' humanity quality. Chin Hospi Manage 2012;32:17-19.

9. Sun T, Gao L, Li F, et al. Workplace violence, psychological stress, sleep quality and subjective health in Chinese doctors: a large crosssectional study. BMJ Open 2017;7:e017182.

10. Ran L, Shuang X, Lu W. Analysis of 1645 cases irrational outpatient Chinese medicine prescriptions intervention. China Med Her 2014;11:154-8.

11. Shi J, Jiang Y, Hu P, et al. A surveying study on social satisfaction to current doctor-patient relationship in China. JSSM 2015;08:695-702.

12. Yao Y, Wang W, Wang F, et al. General self-efficacy and the effect of hospital workplace violence on doctors' stress and job satisfaction in China. Int J Occup Med Environ Health 2014;27:389-99.

13. Lu L, Dong M, Wang SB, et al. Prevalence of workplace violence against Health-Care Professionals in China: a comprehensive meta-analysis of observational surveys. Trauma Violence Abuse 2018:152483801877442.

14. Weiss AP. Workplace Violence against Health Care Workers in the United States. N Engl J Med 2016;375:e14.

15. Schat AC, Kelloway EK. Reducing the adverse consequences of workplace aggression and violence: the buffering effects of organizational support. J Occup Health Psychol 2003;8:110-22.

16. Gong $Y$, Han T, Yin X, et al. Prevalence of depressive symptoms and work-related risk factors among nurses in public hospitals in southern China: a cross-sectional study. Sci Rep 2014;4:7109.

17. Enders $F$, West CP, Dyrbye $L$, et al. Burnout and quality of life among healthcare research faculty. Res Manag Rev 2015;20:92-104.

18. Sundquist J, Johansson SE. High demand, low control, and impaired general health: working conditions in a sample of Swedish general practitioners. Scand J Public Health 2000;28:123-31. 
19. West CP, Tan AD, Habermann TM, et al. Association of resident fatigue and distress with perceived medical errors. JAMA 2009;302:1294-300.

20. Zhao S, Xie F, Wang J, et al. Prevalence of workplace violence against Chinese nurses and its association with mental health: a cross-sectional survey. Arch Psychiatr Nurs 2018;32:242-7.

21. Liu W, Zhao S, Shi L, et al. Workplace violence, job satisfaction, burnout, perceived organisational support and their effects on turnover intention among Chinese nurses in tertiary hospitals: a cross-sectional study. BMJ Open 2018;8:e019525.

22. Chen S, Lin S, Ruan Q, et al. Workplace violence and its effect on burnout and turnover attempt among Chinese medical staff. Arch Environ Occup Health 2016;71:330-7.

23. Schat AC, Kelloway EK. Effects of perceived control on the outcomes of workplace aggression and violence. $J$ Occup Health Psychol 2000;5:386-402.

24. Rogers KA, Kelloway EK. Violence at work: personal and organizational outcomes. J Occup Health Psychol 1997;2:63-71.

25. Luthans F, Human YCM. social, and now positive psychological capital management: investing in people for competitive advantage. Organ Dyn 2004;33:143-60.

26. Luthans F, Youssef CM, Avolio BJ. Psychological capital: Developing the human competitive edge. Oxford University Press, Oxford 2007.

27. Liu L, Chang Y, Fu J, et al. The mediating role of psychological capital on the association between occupational stress and depressive symptoms among Chinese physicians: a cross-sectional study. BMC Public Health 2012;12:1-8.

28. Wang Y, Liu L, Wang J, et al. Work-family conflict and burnout among Chinese doctors: the mediating role of psychological capital. $J$ Occup Health 2012;54:232-40.

29. Wang JN, Sun W, Chi TS, et al. Prevalence and associated factors of depressive symptoms among Chinese doctors: a cross-sectional survey. Int Arch Occup Environ Health 2010;83:905-11.

30. Zhang J, Zhen-Yun WU, Fang G, et al. Development of the Chinese age norms of CES-D in urban area. Chin Ment Health $J$ 2010;24:139-43.

31. Tan JF, Cai JY, Wan CH. Relationship between job burnout and quality of life in doctors and nurses. Chin $J$ Public Health 2012;28:812-4.

32. Wang JH. Epidemiology. 7th edn. Beijing: People's Medical Publishing House, 2011.
33. Ni YY, Zhang JX. How to determine permissible error $\delta$ value properly when computing sample sizes in hypothesis tests. The Journal of Evidence-Based Medicine 2011;11:370-4.

34. Gao F. Factors associated of job burnout among the doctors and nurses in Liaoning province. master's thesis: China Medical University, 2014

35. Radloff LS. The CES-D Scale: a self-report depression scale for research in the general population. Appl Psych Meas 1977;1:385-401.

36. Maslach C, Jackson SE. The measurement of experienced burnout. J Organ Behav 1981;2:99-113.

37. Zhang XC, Huang DS, Guan P. SUBLIN Study Team. Job burnout among critical care nurses from 14 adult intensive care units in Northeastern China: a cross-sectional survey. BMJ Open 2014;4:e004813.

38. Wang P. Study on medical workplace violence and theory model Sichuan university. PHD thesis: Sichuan university, 2006.

39. Pu J, Hou H, Ma R, et al. The effect of psychological capital between work-family conflict and job burnout in Chinese university teachers: testing for mediation and moderation. $J$ Health Psychol 2017;22:1799-807.

40. Wang Z, Liu H, Yu H, et al. Associations between occupational stress, burnout and well-being among manufacturing workers: mediating roles of psychological capital and self-esteem. BMC Psychiatry 2017;17:364.

41. Aiken LR. Proportion of returns in survey research. Educ Psychol Meas 1981;41:1033-8.

42. Jung PK, Won JU, Roh J, et al. Workplace violence experienced by substitute (daeri) drivers and its relationship to depression in Korea. J Korean Med Sci 2015;30:1748-53.

43. Hansen A, Buitendach JH, Kanengoni H. Psychological capital, subjective well-being, burnout and job satisfaction amongst educators in the Umlazi region in South Africa. SA Journal of Human Resource Management 2015;13:1-9.

44. Avey JB, Luthans F, Jensen SM. Psychological capital: a positive resource for combating employee stress and turnover. Hum Resour Manage 2009;48:677-93.

45. Luthans F, Avey JB, Avolio BJ, et al. Psychological capital development: toward a micro-intervention. J Organ Behav 2006;27:387-93. 